\title{
Examination of trisomy 13, 18 and 21 foetal tissues at different gestational ages using FISH
}

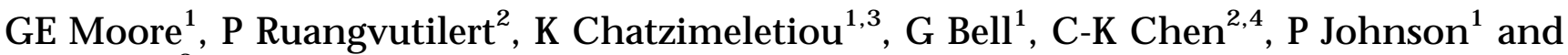 \\ JC Harper $^{2}$
}

\begin{abstract}
${ }^{1}$ Department of Maternal and Fetal M edicine, Division of Paediatrics, Obstetrics and Gynaecology, Imperial College of Science, Technology and M edicine, Queen Charlotte's and Chelsea Hospital; ${ }^{2}$ Department of Obstetrics and Gynaecology, Royal Free and University College Medical School, London, UK; Present addresses: ${ }^{3}$ Department of Obstetrics and Gynaecology, Division of Women and Children's Health, Guy's, King's College and St Thomas' Hospitals Medical and Dental School, London, UK; ${ }^{4}$ Department of Obstetrics and Gynaecology, Chang Gung Memorial Hospital, Lin-Kou Medical Centre, Tao-Yuan, Taiwan.
\end{abstract}

In man high levels of aneuploidy are seen in spontaneous abortions. Very few autosomal trisomies survive to birth, the three most common being those for chromosome 13, 18 and 21 giving rise to the syndromes named Patau, Edwards and Down respectively. Since the majority of these spontaneously abort, what makes the survivors different from the aborters? Could it be that they have tissue specific mosaicism with the additional normal cell line supporting survival? In this study fluorescence in situ hybridisation was used as a convenient way to detect trisomy in interphase cells. To study the level of mosaicism across gestation, different tissues from 21 trisomic foetuses were analysed using probes for chromosome 13, 18, 21, $X$ and $Y$. Two trisomy 18 foetuses exhibited mosaicism. Two others, one trisomy 13 and one trisomy 18 had mosaic placentas. There was no clear association between the limited mosaicism seen and severity of the phenotype. We conclude that at least for this sample set, tissue-specific mosaicism was not likely to be responsible for potential survival to birth. European Journal of Human Genetics (2000) 8, 223-228.

Keywords: trisomy; Edwards syndrome; Patau syndrome; Down syndrome; mosaicism; interphase FISH

\section{Introduction}

Aneuploidy is probably the major reason for pregnancy loss, ${ }^{1}$ with over $60 \%$ of first trimester miscarriages having an abnormal karyotype, half of which are autosomal trisomy. ${ }^{2}$ The majority of aneuploid pregnancies are lost early during gestation with only $5.8 \%$ of still-borns ${ }^{3}$ and $0.59 \%$ of liveborns having a chromosomal defect. ${ }^{4}$ Of those autosomal trisomies that survive to birth, trisomies 13 (Patau syndrome, 1:5000 births), 18 (Edwards syndrome, 1:3000 births) and 21 (Down syndrome 1:700 births) are the most common. ${ }^{5}$ It has been suggested that the presence of a euploid placenta could create an in utero environment that will maintain these

Correspondence: Dr Gudrun E Moore, Department of Maternal and Fetal Medicine, Division of Paediatrics, Obstetrics and Gynaecology, Imperial College of Science, Technology and Medicine, Queen Charlotte's and Chelsea Hospital, Goldhawk Road, London W6 OYG; UK Tel: +448383 5231; Fax: +448383 3922; E-mail: g.moore@rpms.ac.uk Received 1 July 1999; revised 12 November 1999; accepted 16 November 1999 trisomies to birth. In 14 cases of trisomy 13 and 18, a normal cell line (12-100\%) was documented in the cytotrophoblast. However, this was not seen in 12 cases with trisomy $21 .{ }^{6}$ Nevertheless, survival of the small proportion of these trisomies to term and beyond could be due to tissue-specific mosaicism.

Fluorescence in situ hybridisation (FISH) can be used to study chromosome copy number in interphase cell $s^{7}$ and this technique has been used successfully as a rapid alternative to conventional karyotyping. ${ }^{8}$ FISH is also useful in situations where it is difficult to obtain metaphase spreads for karyotyping, such as cancer tissue, ${ }^{9}$ preimplantation embryos ${ }^{10}$ and foetal material after miscarriage. Studies using FISH on preimplantation embryos and first trimester chorionic villus biopsies have shown that chromosomal mosaicism occurs at early stages of development. ${ }^{11-13}$

Analysis of villi from chorionic villus sampling (CVS) has shown that $1-2 \%$ of pregnancies exhibit confined placental mosaicism (CPM) where the karyotype of the placenta is 
different from that of the foetus. ${ }^{14,15}$ One possible explanation is that mitotic error occurs after the differentiation of the embryonic and chorionic compartment. ${ }^{16}$ The chance of mosaicism occurring in the chorionic compartment is greater because $64 \%$ cells are destined to become trophectoderm rather than the inner cell mass or embryo proper. ${ }^{17}$ If mosaicism occurs before the differentiation of those two compartments, the embryo proper might have some control mechanisms to limit the replication of the abnormal cells. This would result in a very low proportion or absence of aneuploid cells in the embryo with mosaicism persisting in the placenta. There could also be some separate mechanism that preferentially allocates abnormal cells to the trophectoderm. ${ }^{18,19}$ In postnatal studies on dysmorphic patients there have been several reports of different proportions of abnormal cell lines in lymphocytes vs skin fibroblasts. ${ }^{20-23}$ In some instances, mosaicism is confined to a specific organ, or present in various percentages in different organs. ${ }^{24,25}$ In addition, karyotyping at different ages in mosaic patients have shown a decrease in the number of abnormal cells with time. ${ }^{20,23,26}$ This implies a selective advantage for the euploid cell.

Most of these studies were based on conventional karyotyping. In our study interphase FISH has been used to examine samples from foetuses with trisomies 13,18 and 21 to evaluate the level of mosaicism in different tissues across gestation. As the tissue had been snap-frozen conventional karyotyping could not be performed. Given the difficulty of studying tissues from trisomic patients that survive to and beyond birth, our cohort contained 21 foetal sample sets with over half from mid to late second trimester. This represents a population that would most likely have survived to term. If mosaicism was found could it be related to the severity of the phenotype and the capacity to survive to and beyond birth?

\section{Materials and methods \\ Sample preparation}

Samples of foetal tissue from different organs were collected after therapeutic terminations at 11-26 weeks of gestation. Twenty-one cases were examined-four cases due to trisomy 13, 10 cases of trisomy 18, and 7 cases with trisomy 21 . Placenta, lung, brain, muscle, kidney, liver, gut, heart, skin, and adrenal tissues were studied. Not all the tissues were collected from every pregnancy. Frozen tissues from euploid pregnancies were also collected and studied in the same manner.

Foetal tissues were snap-frozen immediately and stored at $-80^{\circ} \mathrm{C}$. Samples were prepared with a cut tissue surface dabbed on to a clean slide. In each of the four repeats different areas within the frozen blocks were sampled. The slide was flooded with fixative (3:1 methanol : acetic acid), allowed to dry, flooded with $70 \%$ acetic acid, allowed to dry and dehydrated through an ethanol series.
A control slide was prepared for each FISH from a normal male lymphocyte culture and hybridised in parallel. In addition, three skin fibroblast cultures from foetuses trisomic for chromosome13, 18 and 21 were analysed in both metaphase and interphase to assess the accuracy of detection of the signals in interphase. The collection of the tissues for this study had maternal consent and local ethical committee approval (Project registration 94/4290).

\section{Fluorescence in situ hybridisation}

FISH was performed as described previously. ${ }^{27}$ The sex of the foetuses was determined in placenta using probes for the $X$ and $Y$ chromosomes. This was to verify the karyotypic data and to rule out any maternal contamination (which is only possible for male foetuses); see Tables 1 and 6 . All probes were obtained from (Vysis UK Ltd, Richmond, UK). CEP18, Spectrum Aqua (al pha satellite D18Z1) probe hybridises to the centromere region of chromosome18 (18p11.1-q11.1). CEPX Spectrum Green (alpha satellite DXZ1) probe hybridises to the centromere region of chromosome $X$ (Xp11.1-q11.1). CEPY Spectrum Orange (alpha satellite DYZ3) probe hybridises to the centromere region of chromosome Y (Yp11.1-q11.1). LSI 13 Spectrum Green LSI 13 RB-1, probe hybridises to the long arm of chromosome13, 13q14. LSI 21 Spectrum Orange (Loci D21S259, D21S341, D21S342) probe hybridises to the long arm of chromosome21, region 21q22.13-q22.2. The FISH images were visualised using Zeiss Axioscope fluorescence microscope and captured using a cool, coupled, charged device camera (photometrics) and analysed using Smartcapture software.

To test the variation in sensitivity of the technique between interphase and metaphase a trisomic fibroblastoid cell line was analysed for chromosomes 13, 18 and 21. Over 2400 interphases were counted and compared with $>30$ metaphases per trisomy (see Table2).

Each trisomic frozen tissue sample was hybridised four times independently and > 300 interphase nuclei were counted on each side. Four different operators carried out these experiments. They all did several blind studies using the same tissues and similar probes. Differences in the scoring were within the standard deviations found. The accepted criterion for separate signals is that the signals needed to be more than one signal-distance apart. ${ }^{28}$ The percentage mean of the cells with three signals was compared with the mean found in the interphase of the trisomic fibroblast cultures (see Tables 3-5).

\section{Results}

The clinical details and conventional cytogenetic results at CVS or amniocentesis are presented in Tablel. In every case the initial cytogenetic analysis demonstrated that all the metaphases examined were trisomic. The sexing of the foetal tissue by FISH verified the sexing from the cytogenetic data 
Table 1 Conventional cytogenetic and clinical features of the cases in the study

\begin{tabular}{|c|c|c|c|c|c|}
\hline \multirow[t]{2}{*}{ Patient } & \multirow{2}{*}{$\begin{array}{l}\text { Maternal } \\
\text { age }\end{array}$} & \multirow{2}{*}{$\begin{array}{l}\text { Gestation } \\
\text { (wks) }\end{array}$} & \multicolumn{2}{|c|}{ Cytogenetic } & \multirow[t]{2}{*}{ Clinical data } \\
\hline & & & Cell count & Karyotype & \\
\hline 13.1 & 31 & 19 & 5 CVS & $47, X X+13$ & multiple abnormalities \\
\hline 13.3 & 42 & 23 & 5 CVS & $47, X X+13$ & cleft palate, hydronephrosis, rockerbottom feet, exomphalos \\
\hline 13.4 & 26 & 26 & $10 \mathrm{FB}$ & $47, X X+13$ & multiple abnormalities \\
\hline 18.1 & 43 & 11 & 5 CVS & $47, X X+18$ & no abnormalities seen at US or TOP \\
\hline 18.3 & 46 & 13 & 5 CVS & $47, X X+18$ & no abnormalities seen at US or TOP \\
\hline 18.4 & 38 & 13 & $10 \mathrm{CVS}$ & $47, X Y+18$ & no data \\
\hline 18.5 & 44 & 13 & 7 CVS & $47, X X+18$ & no data \\
\hline 18.6 & 39 & 16 & 5 CVS & $47, X Y+18$ & multiple abnormalities on US \\
\hline 18.7 & 41 & 18 & $5 \mathrm{~A}$ & $47, X X+18$ & low set ears, rockerbottom feet \\
\hline 18.8 & 42 & 18 & $5 \mathrm{~A}$ & $47, X X+18$ & multiple abnormalities on US \\
\hline 18.9 & 45 & 18 & 5 CVS & $47, X X+18$ & mild phenotype, rockerbottom feet \\
\hline 18.10 & 33 & 20 & 5 CVS & $47, X Y+18$ & multiple abnormalities on US \\
\hline 21.2 & 38 & 15 & 10 CVS & $47, X Y+21$ & no data \\
\hline 21.3 & 31 & 17 & 15 CVS & $47, X X+21$ & no abnormalities detected by US \\
\hline 21.4 & 42 & 17 & $15 \mathrm{~A}$ & $47, X X+21$ & no abnormalities detected by US \\
\hline 21.5 & 40 & 17 & $15 \mathrm{~A}$ & $\begin{array}{l}47, X Y, \operatorname{inv}(8) \\
(p 23.1 q 23.2),+21\end{array}$ & no data \\
\hline 21.6 & 31 & 18 & $15 \mathrm{~A}$ & $47, X X+21$ & a small ventricular septum defect \\
\hline 21.7 & 38 & no data & $10 \mathrm{CVS}$ & $47, X Y+21$ & no data \\
\hline
\end{tabular}

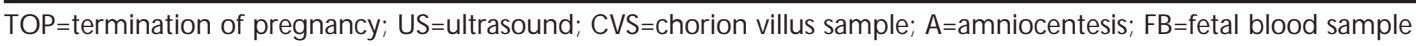

Table 2 Cells with three signals out of total cells counted from trisomic fibroblast cultures ( 3 separate lines for each trisomy and 8 separate counts per trisomy

\begin{tabular}{|c|c|c|c|c|}
\hline & \multicolumn{2}{|c|}{ Interphase cells } & \multicolumn{2}{|c|}{ M etaphase cells } \\
\hline & $\begin{array}{l}\text { percentages } \\
(\text { mean } \pm \text { S.D.) }\end{array}$ & $\begin{array}{l}\text { cells counted } \\
\text { (total) }\end{array}$ & $\begin{array}{l}\text { percentages } \\
\text { (mean士S.D.) }\end{array}$ & $\begin{array}{l}\text { cells counted } \\
\text { (total) }\end{array}$ \\
\hline Trisomy 13 & $88.40 \pm 4.0$ & 2449 & 100 & 32 \\
\hline Trisomy 18 & $78.93 \pm 4.7$ & 2652 & 100 & 31 \\
\hline Trisomy 21 & $87.97 \pm 3.4$ & 2422 & 100 & 55 \\
\hline
\end{tabular}

Table 3 Percentage mean plus standard deviation of cells with three signals from trisomy 13 samples and with two signals in the normal euploid tissue controls (repeats $n=4$ )

\begin{tabular}{|c|c|c|c|c|c|c|c|c|}
\hline Case & Placenta & Lung & Brain & Muscle & Kidney & Liver & Gut & Adrenal \\
\hline 13.1 & $93.8 \pm 0.7$ & & $95.5 \pm 0.3$ & & & & & \\
\hline 13.2 & $93.8 \pm 1.3$ & & $96.6 \pm 0.6$ & & & $94.8 \pm 0.5$ & & $98.1 \pm 0.3$ \\
\hline 13.3 & $40.4 \pm 3.5$ & $92.2 \pm 0.3$ & & $94.6 \pm 0.6$ & & $91.2+1.5$ & & \\
\hline Norm & $94.0 \pm 2.0$ & $96.8 \pm 1.7$ & $97.6 \pm 0.6$ & $96.3 \pm 0.7$ & $97.0 \pm 0.4$ & $95.7 \pm 1.4$ & $96.1 \pm 0.3$ & $98.3 \pm 0.5$ \\
\hline
\end{tabular}

Norm: normal euploid tissues from termination of pregnancy in late second trimester; mosaic values in bold.

with the exception of 18.6 where maternal contamination is suspected in the placenta.

The skin fibroblast cultures from foetuses with trisomy 13, 18 and 21 respectively were all fully trisomic after counting at least 30 metaphases. The average percentages of cells with three signals for each trisomy derived from counting interphase cells were $10 \%$ to $20 \%$ lower. The number for trisomy 18 was lower than that for trisomy 21 and 13 (79\% vs $88 \%)$. The chromosome18 probe is an alpha-satellite probe, giving a larger signal and more chance of overlap of the signals in interphase. These fibroblast culture interphase values represent the controls to which the interphase counts from the frozen trisomic tissue would be compared. A score of $80 \%$ for chromosome 18 and $90 \%$ for chromosomes 13 and 21 would indicate a full trisomic line in that tissue (see Table2).

Tables 3-5 show the mean percentages from each tissue from the frozen trisomic samples. The figures for trisomy 18 were in the range of $65-85 \%$ while the ones for trisomy 21 were $85-95 \%$ and for trisomy 13 were $90-95 \%$. One foetus was considered to be mosaic in the trisomy 18 group (18.9). From the two tissues available, liver and gut, only $45 \%$ of cells had three signals. Also, 18.10 showed a $61 \%$ level of trisomy 18 in brain, clearly lower than the expected $79 \%$. 
Table 4 Percentage mean plus standard deviation of cells with three signals from trisomy 18 samples with two signals in the normal euploid tissue controls (repeats $n=4$ )

\begin{tabular}{|c|c|c|c|c|c|c|c|c|c|}
\hline Case & Placenta & Lung & Brain & Muscle & Kidney & Liver & Gut & Heart & Skin \\
\hline 18.1 & $84.2 \pm 1.2$ & $70.6^{a}$ & $68.7^{a}$ & & & & & & \\
\hline 18.2 & $74.0 \pm 3.9$ & & & $80.2 \pm 1.3$ & & & & & \\
\hline 18.3 & $74.6 \pm 2.5$ & & $76.3 \pm 2.7$ & $76.5 \pm 1.7$ & & & & & \\
\hline 18.5 & $74.7 \pm 6.5$ & & & $76.1 \pm 5.4$ & & & & & \\
\hline 18.6 & $42.0 \pm 1.9$ & $84.5 \pm 2.9$ & $75.7 \pm 3.0$ & & $80.1 \pm 0.5$ & & & & \\
\hline 18.7 & $67.1 \pm 4.5$ & $77.4 \pm 2.2$ & $69.6 \pm 1.2$ & & & & & & \\
\hline 18.8 & $80.4 \pm 1.2$ & & $68.2 \pm 2.5$ & $78.7 \pm 3.6$ & & & & & \\
\hline 18.9 & & & & & & $45.6 \pm 6.3$ & $44.9 \pm 1.9$ & & \\
\hline 18.10 & $70.8 \pm 4.6$ & & $61.2 \pm 4.3$ & & $81.4 \pm 2.7$ & & & & \\
\hline Norm & $91.3 \pm 0.5$ & $93.0 \pm 2.6$ & $92.0 \pm 0.8$ & $89.4 \pm 2.6$ & $90.0 \pm 2.6$ & $96.3 \pm 0.6$ & $91.3 \pm 0.5$ & $97.7 \pm 0.6$ & \\
\hline
\end{tabular}

atissue only hybridised once due to scarcity; Norm: normal euploid tissues from termination of pregnancy in late second trimester; mosaic values in bold.

Table 5 Percentage mean plus standard deviation of cells with three signals from trisomy 21 samples with two signals in the normal euploid tissue controls (repeats $n=4$ )

\begin{tabular}{llllll}
\hline Patient & Placenta & Lung & Brain & Heart & Skin \\
\hline 21.1 & $92.0 \pm 2.8$ & $90.0 \pm 2.8$ & $94.0 \pm 4.4$ & & \\
21.2 & $86.0 \pm 3.2$ & & $87.0 \pm 2.8$ & 93.8 \\
21.3 & $86.7^{\mathrm{a}}$ & $86.8^{\mathrm{a}}$ & $86.6^{\mathrm{a}}$ & $90.9^{\mathrm{a}}$ & \\
21.4 & $84.0 \pm 5.2$ & $88.0 \pm 2.8$ & $87.0 \pm 2.0$ & $95.0 \pm 4.4$ & \\
21.5 & & & $88.7 \pm 3.0$ & $91.0 \pm 2.7$ & \\
21.6 & $92.0 \pm 0.5$ & $90.0 \pm 1.3$ & $92.0 \pm 1.5$ & $89.0 \pm 2.8$ & $90.9 \pm 1.2$ \\
21.7 & $91.0 \pm 3.2$ & & $95.0 \pm 2.4$ & $96.6 \pm 0.6$ & $95.0 \pm 0.5$ \\
Norm & $94.3 \pm 1.5$ & $95.5 \pm 0.6$ & $95.0 \pm 1.7$ & $96.6 \pm 0.9$
\end{tabular}

atissue only hybridised once due to scarcity; Norm: normal euploid tissues from termination of pregnancy in late second trimester.

Mean percentages of trisomic signals in the placentas of cases 13.3 and 18.6 were also low. When studying placenta, maternal cell contamination should be considered. As foetus 13.3 was female, maternal cell contamination by sexing could not be ruled out. However, meticulous precaution was observed to avoid the problem by using only a freshly cut surface to dab on the slide. Another possible explanation for this case is CPM. Concerning case 18.6 the foetus was unambiguously male but the placenta had $40 \%$ diploid female cells (Table6). Given the high level of female cells, maternal cell contamination was the most likely explanation. The level of trisomy 18 (72\%) in the male cells was not mosaic.

The remaining trisomic tissues analysed were all in the $90 \%$ range for chromosome 13 , the $70-80 \%$ range for chromosome 18 and the $80-90 \%$ range for chromosome 21 , indicating that the foetuses were not mosaic. In the normal frozen tissue, thelevels of euploidy were greater than $90 \%$ for all the probes. This is higher than the interphase data from the control fibroblastoid trisomic lines but the overlap of one of three signals is more likely than one of two.

Table 6 Percentage of trisomic signals in the placenta for male foetus (18.6) (XY : XX cells approximately $55: 40) n=4$

\begin{tabular}{llcl}
\hline & $\begin{array}{l}\text { Total cells } \\
\text { counted }\end{array}$ & $\begin{array}{l}\text { Percentage } \\
\text { XX181818 }\end{array}$ & $\begin{array}{l}\text { Percentage } \\
\text { XX1818 }\end{array}$ \\
\hline Female cells & 481 & $5.57( \pm 2.28)$ & $88.10( \pm 4.92)$ \\
Male cells & 727 & $71.72( \pm 4.33)$ & $26.61( \pm 4.31)$ \\
\hline
\end{tabular}

\section{Discussion}

It is interesting to speculate why only a small percentage of Down, Patau and Edwards syndromes survive to term. Given the percentage that spontaneously abort, one theory is that the survivors are in fact mosaic and the level of normal cells in different tissues enhances survival. It is widely believed that many surviving Turner syndrome individuals $(45, X)$ are mosaics with a normal cell line. ${ }^{29}$ This hypothesis is supported by the known fertility in a considerable number of Turner syndrome cases, implying gonadal mosaicism. ${ }^{30}$ The published levels of mosaicism in lymphocytes for trisomies 13, 18 and 21 in the literature are $<10 \%, 10 \%$ and $1 \%$ respectively but this does not rule out tissue-specific mosaicism. ${ }^{31}$ Mosaicism is most commonly found for chromosome 18 and these known mosaics have variable phenotypes from normal intellect to severe malformations. ${ }^{32}$ The analysis of tissue-specific mosaicism is very difficult in living cohorts. Using interphase FISH on tissue samples from a deceased neonate with unexplained abnormalities, a 17\% trisomy 18 line was found in liver but was not in lymphocytes, fibroblasts or kidney. ${ }^{25}$

In this study we have exploited interphase FISH to look at frozen tissues from trisomic abortuses. By comparing the sensitivity of detection of three signals between interphase and metaphase in trisomic fibroblast cell lines a $20 \%$ reduction was seen in interphase. This fall in sensitivity of detection from cytogen etic metaphase spreads to analyses by FISH in interphase is not a new finding and has been shown in other studies. ${ }^{33-35}$ 
Of the 21 foetuses analysed, two had mosaic placentas, one had apparent true mosaicism of chromosome18 in the two available tissues, with a further foetus showing a reduced level of trisomy in the brain. This level of $10 \%$ mosaicism in Edwards syndrome is similar to that documented in the literature. ${ }^{36}$

The clinical features of the cases varied. All four cases of trisomy 13 had multiple abnormalities and a high level of trisomy in the tissues studied. One had a mosaic placenta but as the foetus was female, the possibility of maternal contamination could not be excluded. Similarly, all the cases of trisomy 18 diagnosed in mid-trimester exhibited ultrasound findings suggestive of Edwards syndrome. Cases 18.1-18.5 were all diagnosed on first trimester CVS performed because of advance maternal age, and therefore detailed ultrasound was not performed. The foetus with mosaicism in liver and gut (18.9) demonstrated the mildest phenotype on scan. The mosaicism in placenta of foetus 18.6 is likely to be maternal contamination and therefore not related to the phenotype. Foetus (18.10) had a lower level of trisomy in the brain and multiple abnormalities. None of the trisomy 21 cases were found to be mosaic in any of the tissues analysed. As all the pregnancies in this study were interrupted, it is only an assumption that they would have progressed to term. It is therefore a possibility that other surviving trisomies are tissue-specific mosaics. However, four cases were 20 + weeks' gestation which would have had a $70 \%$ chance of survival to term. ${ }^{37}$ All except one of the trisomic foetuses studied showed high levels of trisomy from interphase FISH. We conclude that the potential survival of these trisomies is not necessarily related to tissue-specific mosaicism. However, as only one site in the placenta of these late second trimester foetuses were analysed it is impossible to rule out CPM. It is more likely that the mechanism of survival in some cases is tolerance of an extra chromosome in all tissues and/or placental mosaicism. If the former is true in isolation, why so many abort in utero remains unanswered.

\section{Acknowledgements}

The authors would like to thank Professor Joy Delhanty (UCL) for critical reading of the manuscript and Stephen Webber-Hall, Vysis (UK) Ltd for practical assistance and advice with the Smartcapture software. We are also grateful to Professor Dagmar Kalousek for her kind advice on queries about confined and placental mosaicism. GEM and PR contributed equally to this work.

\section{References}

1 Boue J, Philippe E, Giroud A, Boue A: Phenotypic expression of lethal chromosome anomalies in human abortuses. Teratology 1976; 44: 3-20.

2 Boue J, Boue A, Lazar P: Retrospective and prospective epidemiological studies of 1500 karyotyped spontaneous human abortions. Teratology 1975; 12: 11-26.

3 Machin GA, Crolla JA: Chromosome constitution of 500 infants dying during the perinatal blood. Humangenetik 1974; 23 : 183-198.
4 Jacobs PA: Epidemiology of chromosome abnormalities in man. Am J Epidemiol 1977; 105: 180-191.

5 Jones KL: Recognisable patterns of malformation. In: Smiths Recognisable Patterns of Human Malformation, 5th edn. WB Saunders: Philadelphia, USA 1997, pp 8-18.

6 Kalousek DK, Barrett IJ, McGillivray BC: Placental mosaicism and intrauterine survival of trisomies 13 and 18. Am J Hum Genet 1989; 44: 338-343.

7 Cremer T, Landegent J, Bruckner A et al: Detection of chromosome aberrations in the human interphase nucleus by visualization of specific target DNAs with radioactive and nonradioactive in situ hybridisation techniques: diagnosis of trisomy 18 with probe L1.84. Hum Genet 1986; 74: 346-352.

8 Eiben B, Trawicki W, Hammans W, Goebel R, Pruggmayer M, Epplen JT: Rapid prenatal diagnosis of aneuploidies in uncultured amniocytes by fluorescence in situ hybridisation. Fetal Diagn Ther 1999; 14: 193-197.

9 Popescu NC, Zimonjic DB: Molecular cytogenetic characterization of cancer cell alterations. Cancer Genet Cytogenet 1997; 93: 10-21.

10 Harper JC, Delhanty JD: Detection of chromosomal abnormalities in human preimplantation embryos using FISH. J Assist Reprod Genet 1996; 13: 137-139.

11 Munne S, Weier HUG, Grifo J, Cohen J: Chromosome mosaicism in human embryos. Biol Reprod 1994; 51: 373-379.

12 Harper JC, Coonen E, Handyside AH, Winston RML, Hopman AH, Delhanty JDA: Mosaicism of autosomes and sex chromosomes in morphologically normal, monospermic preimplantation human embryos. Prenat Diagn 1995; 15: 41-49.

13 Delhanty JDA, Harper JC, Ao A, Handyside AH, Winston RML: Multicolour FISH detects frequent chromosomal mosaicism and chaotic division in normal preimplantation embryos from fertile patients. Hum Genet 1997; 99: 755-760.

14 Simoni G, Sirchia SM: Confined placental mosaicism. Prenat Diagn 1994; 14: 1185-1189.

15 Kalousek D, Vekemans M: Confined placental mosaicism. J Med Genet 1996; 33: 529-533.

16 Crane JP, Cheung SW: An embryonic model to explain cytogenetic inconsistencies observed in chorionic villus versus fetal tissue. Prenat Diagn 1988; 8: 119-129.

17 Hardy K, Handyside AH, Winston RML: The human blastocyst: cell number, death and allocation during late preimplantation development in vitro. Development 1989; 107: 597-604.

18 James RM, Klerk AH, Keighren M, Flockhart JH, West JD: Restricted distribution of tetraploid cells in mouse tetraploid $<==>$ diploid chimaeras. Dev Biol 1995; 167: 213-226.

19 James RM, West JD: A chimaeric animal model for confined placental mosaicism. Hum Genet 1994; 93: 603-604.

20 Reyes PG, Hsu LY, Strauss L, Rose J, Hirschhorn K: Trisomy 8 mosaicism syndrome. Report of monozygotic twins. Clin Genet 1978; 14: 90-97.

21 Pagon RA, Hall JG, Davenport SL, Aase J, Norwood TH, Hoehn $\mathrm{HW}$ : Abnormal skin fibroblast cytogenetics in four dysmorphic patients with normal lymphocyte chromosomes. Am J Hum Genet 1979; 31: 54-61.

22 Metaxotou C, Tsenghi C, Bitzos I, Strataki-Benetou M, KalpiniMavrou A, Matsaniotis N: Trisomy 3 mosaicism in a live-born infant. Clin Genet 1981; 19: 37-40.

23 Bass HN, Fox M, Wulfsberg E, Sparkes RS, Crandall BF: Trisomy 18 mosaicism: clues to the diagnosis. Clin Genet 1982; 22: 327-330.

24 Yokoyama Y, Narahara K, Kamada M, Tsuji K, Seino Y: Tissuespecific mosaicism for trisomy 21 and congenital heart disease. J Pediatr 1992; 121: 80-82.

25 Shashi V, Golden WL, von Kap-Herr C, Wilson WG: Constellation of congenital abnormalities in an infant: a new syndrome or tissue-specific mosaicism for trisomy 18? Am J M ed Genet 1996; 62: 38-41.

26 Gravholt $\mathrm{CH}$, Friedrioch U, Nielsen J: Chromosomal mosaicism: a follow-up study of 39 unselected children found at birth. Hum Genet 1991; 88: 49-52. 
27 Harper J, Delhanty J: FISH in preimplantation diagnosis. In: Walker J (ed.). M ethods in M olecular M edicine: Molecular Diagnosis of Genetic Diseases. Humana Press: New Jersey, USA, 1996, pp 259-268.

28 Hopman AHN, Raemakers FCS, Raap AK et al: In situ hybridisation as a tool to study numerical chromosome aberrations in solid bladder tumours. Histochemistry 1988; 89: 307-316.

29 Amiel A, Kidron D, Kedar I, Gaber E, Reish O, Fejgin MD: Are all phenotypically normal Turner syndrome foetuses mosaics? Prenat Diagn 1996; 16: 791-795.

30 Mazzanti L, Cacciari E, Bergamaschi R et al: Pelvic ultrasonography in patients with Turner syndrome: age-related findings in different karyotypes. J Pediatr 1997; 131: 135-140.

31 Gilbert-Barnes EF, Opitz JM: Chromosome abnormalities. In: Wigglesworth JS, Singer DB (eds). Textbook of Fetal and Perinatal Pathology. Blackwell: UK, 1998, pp 293-303.

32 Baty BJ, Blackburn BL, Carey JC: Natural history of trisomy 18 and 13I. Growth, physical assessment, medical histories, and recurrence risk. Am J Med Genet 1994; 49: 175-188.
33 Klinger K, Landes G, Shook D et al: Rapid detection of chromosome aneuploidies in uncultured amniocytes by fluorescence in situ hybridisation (FISH). Am J Hum Genet 1992; 51: 55-65.

34 Ward BE, Gersen SL, Carelli MP et al: Rapid prenatal diagnosis of chromosomal aneuploidies by fluorescence in situ hybridisation: clinical experience with 4,500 specimens. Am J Hum Genet 1993; 52: 854-865.

35 Bryndorf T, Christensen B, Vad M, Parner J, Brocks V, Philip J: Prenatal detection of chromosome aneuploidies by fluorescence in situ hybridisation: experience with 2000 uncultured amniotic fluid samples in a prospective preclinical trial. Prenat Diagn 1997; 17: 333-341.

36 Zellweger WW, Simpson J: Chromosomes of Man. JB Lippincott: Philadelphia, 1977.

37 Snijders RJM, Sebire NJ, Nicolaides KH: Maternal age and gestational age-specific risk for chromosomal defects. Fetal Diagn Ther 1995; 10: 365-367. 